\title{
FIRE PROTECTION IN VARIOUS TYPES OF WOODEN STRUCTURES
}

\author{
Stanislava GAŠPERCOVÁ ${ }^{1, *}$, Linda MAKOVICKÁ OSVALDOVÁ ${ }^{1}$, \\ ${ }^{1}$ Department of Fire Engineering, Faculty of Security Engineering, University of Žilina, ul. 1. Mája 32, \\ 01026 Žilina. \\ corresponding author: stanislava.gaspercova@fbi.uniza.sk, +421-4-1513-6796.
}

\section{Abstract}

Design of new modern systems for low energy efficient construction in a passive, zero standard or energy-autonomous buildings, as well as the increased popularity of solid wood construction means intervention into the very structure of its statics, building physics, but also fire properties. Some prototype design solutions are not verified whether the tests, by good computational analysis or verification of long-term use of the building. In the context of changing standards in building design, new approaches are needed. If in wooden buildings the potential risk of fire is higher than other buildings, we need special methods, materials and practical skills.
\end{abstract}

\author{
Keywords: \\ Wooden building; \\ Fire protection; \\ Fire resistant; \\ Types of construction system; \\ Wooden structures.
}

\section{Introduction}

In 1989, the Commission and the Member States of the EU have accepted, on the basis of agreements, Eurocodes and regulations, the reference documents for the following purposes:

- as means to demonstrate compliance of buildings and civil engineering works with the essential requirements of Council Directive 89/106 / EEC, in particular the basic requirements:

- No. 1 - mechanical resistance and stability and essential requirements,

- No. 2 - fire safety,

- as a basis for the award of contracts for the construction and related engineering services,

- as a framework curriculum for the preparation of harmonized technical specifications for construction products [1].

The second requirement of the EU about construction products is concerned about spread of fire and smoke and the load of construction. These requirements are satisfied by evidence of fire resistance of bearing or separating elements. The issue of fire protection is so specifically defined for all types of buildings. Fire resistance is the decisive criterion, since it ultimately decides on the material composition, spatial resolution and fire-safety measures.

\section{Characteristic of fire resistance}

Fire resistance is the ability of the building element to withstand the effects of fire and maintain their properties for a specified time. The structure as effect of fire is fixed on the standard values, which depend on a number of criteria such as the quantity of flammable material, the second structural unit, the type of construction and others. Various elements are determined as criteria during this period and must be provided. For example, in the context of supporting structures, it is necessary to provide at least their capacity, integrity and insulation. When cladding, it is only needed to ensure their integrity and insulation. The criteria for fire closures differ from their location in the building to the function they provide the building.

Different levels of heat exposure reflect different fire scenarios, which prescribe their translation into practical tests and indicate tolerance for their application. There are other temperature curves as indicated [2], for example, hydrocarbon curve and the curve for extreme fire scenarios (e.g. road tunnels, nuclear plant) which may impose more than stringent agreed criteria. The oldest and the bestknown and the most widely used temperature curve is the standard curve of temperature / time (volume of fire outbreak), as a relation to a real fire is shown in Fig. 1. As a basis for testing, there will 
be used the normalized temperature dependence / time to be applied to the entire duration of the test. Dependence, which is a model of a fully developed fire in the space, is given by the formula (1). Further details of the practical application of this curve, and other test parameters, such as tolerances, are given in EN 1363-1 [3].

$T=365_{\log 10}(8 t+1)+20$,

where: $t-$ time at the beginning of the test $(\mathrm{min})$,

$T$ - average temperature $\left({ }^{\circ} \mathrm{C}\right)$.

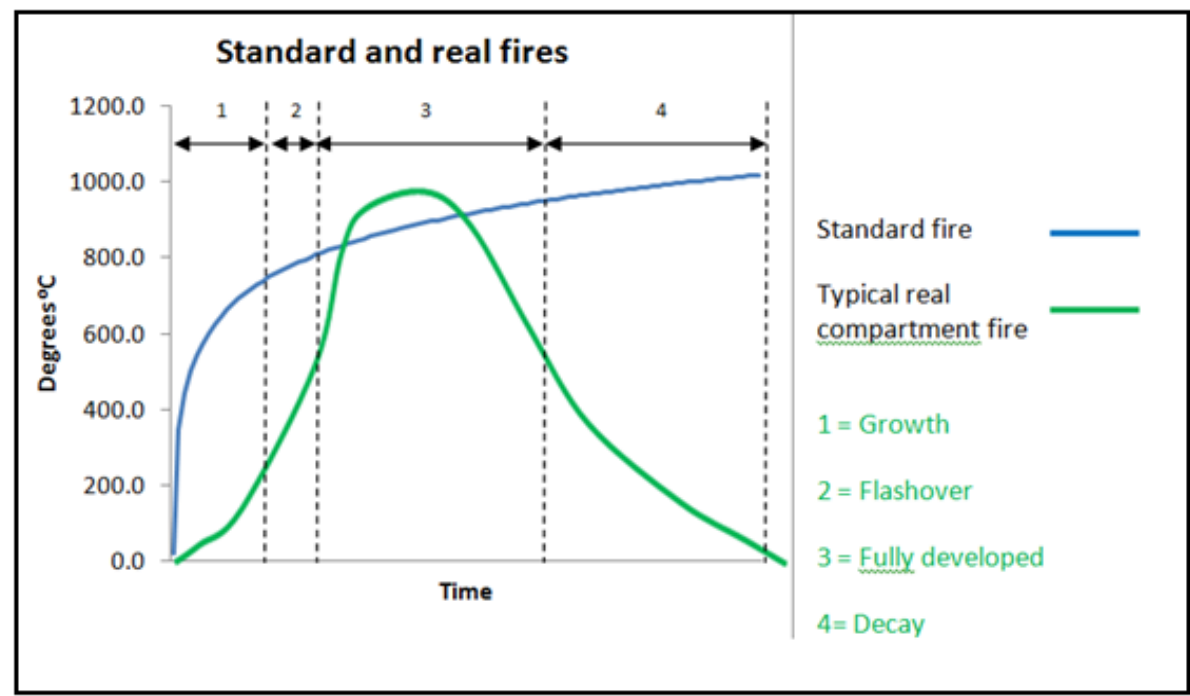

Fig. 1: The relationship of standard curve temperature / time to real fire [3].

\section{Types of structure systems}

The structure system includes these types of systems: pillar structure system, panel construction, the construction system of composite fittings and cladding with a carrier layer of glued wood.

\subsection{Pillar structure system}

The basis of the current standard of the pillar construction is the standard system framework derived from a two-by-four system. External part of the wall is covered by thermal insulation or thermal insulation which is creating ventilated spaces in order to increase the thermal resistance of the wall and interrupted thermal bridges. From the interior side, there can be added an additional insulation layer with the thickness up to $80 \mathrm{~mm}$, which is also used as a connector layer (see Fig. 2). Passive houses require the insulation thickness within the range of $280 \mathrm{~mm}$ and more. In order to save material and to eliminate thermal bridges, there are used box profiles instead of solid wood profiles of profiles and sections I, inside of which they are filled with thermal insulation. Profiles composite cross sections are also preferred in terms of statics and in terms of deformation.

The application of thin-walled beams is experiencing a renaissance in recent years due to beams which are industrially produced from the wall of oriented strand board (OSB). In addition to these technical OSB classes 3 and 4, they should be applied as walls and hardboard technical classes HB.HLA2 and MBH.LA2. Plywood is currently not used in the walls of beams for economic reasons. Beam flange should be made of solid wood or laminated construction timber $(\mathrm{KVH})$. The risks in this structure are cross-sectional pillars. Fire resistance of each structure (the maintenance of any limit state) is given by two essentially separate ways. By sheathing and supporting structure. Covering syntactically will probably meet the fire resistance. After the severance of the shell, it opens the supporting pillar structure of small cross section, which can easily, because of the fire, lose the stability. This phenomenon may occur even in the case of the fire resistance testing. 
The Buchanan studies [4] showed the risk of burning of the carrier elements and reducing of their diameter. Interestingly, even small leaks can cause rapid melt-down (see Fig. 3).

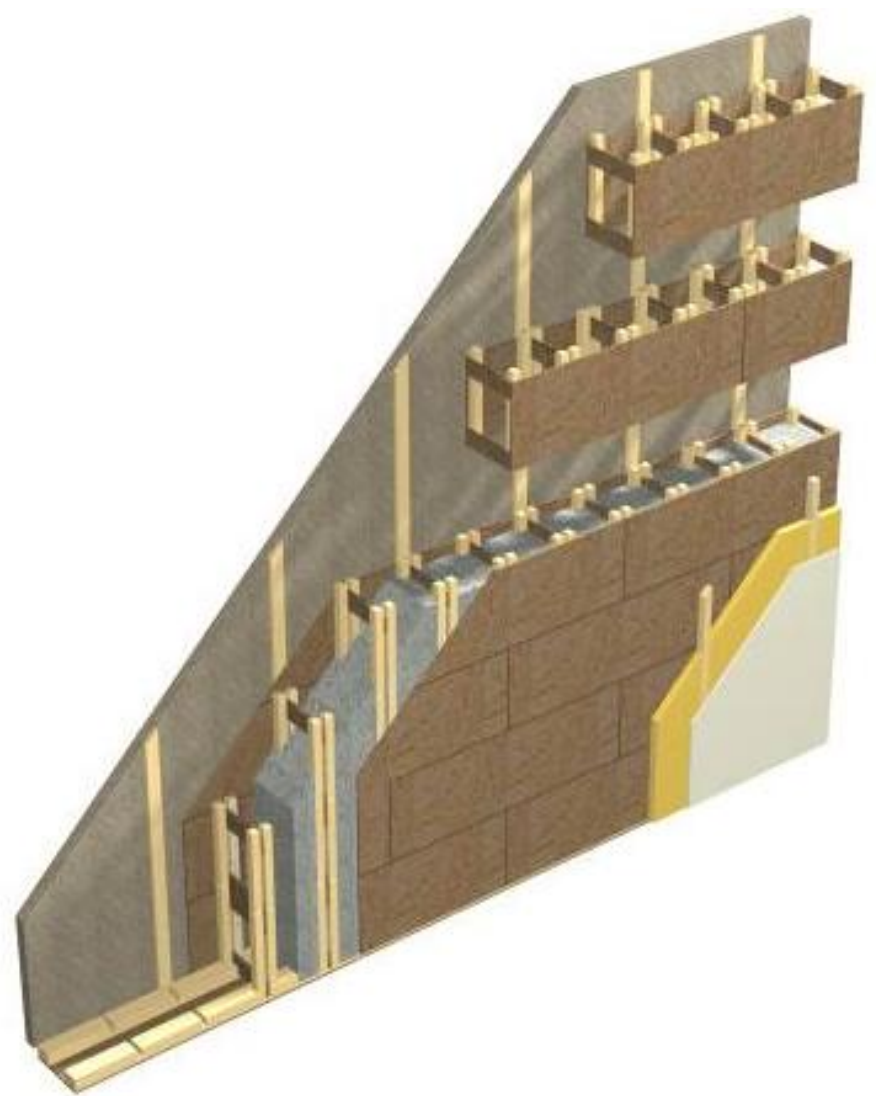

Fig. 2: Types of wall frame construction of composite cross-sections - I profiles [5].

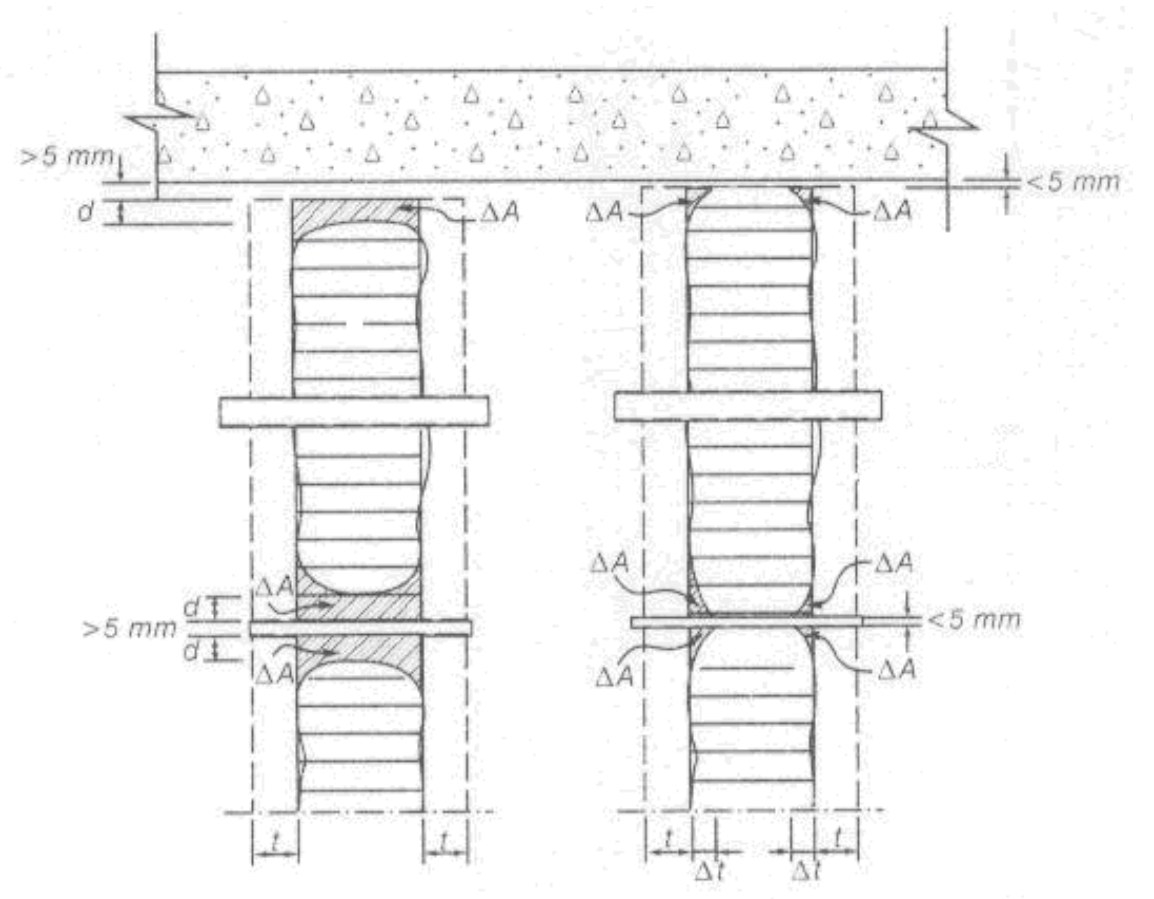

Fig. 3: Effect of contact sheathing - thickness gaps in the bearing of burning time [5]. 
In this system, in addition to construction solving, there occurs a "material" problem. If the supporting structure had been made from a solid wood or wood glued elements, the support structure would be a beam with OSB boards that otherwise responds to the fire and brings other fire resistance properties $[6,7]$. The positive information is that they burn later, however they have series of negative properties, such as higher calorific value, very difficult to extinguish, after quenching it is easily to flare up again and so on. In these structures, it will be necessary to carry out tests on the fire resistance of the certified institution. During the construction, we must carry on a quality of the work as well as the application of fire-extinguishing and other fire protection systems and measures.

\subsection{Panel Construction System}

In terms of static operation, thermal performance and airtightness, there are the same construction principles as in the pillar structures. It must, however, also cover the transport and assembly expense. In order to achieve passive standard, they must be taken into the thermal barrier and sufficient insulation thickness.

From the fire point of view, there can be assumed the mass production of panels tested for fire resistance. While maintaining the quality of the starting materials, the only problem seems to be the point of contact panels, design of these joints and custom design. Quality traffic panel shows weaknesses of buildings not only from the fire point of view. Testing joints of panels is not a requirement to test fire resistance, although it should be encouraged and tests could provide new knowledge about the behavior of the design and used materials.

\subsection{The construction system of composite fittings}

The basis of this modular construction system is the fitting, which is based on the determined system of coordination, the spatial load-bearing walls, the roof and the horizontal elements. The addition to transmitting horizontal forces provides spatial rigidity and stability of the building, which is ensured by a special combination of solutions and additional reinforcements. Lightweight fittings allow fast installation without the use of special equipment. The method of construction using prefabricated fittings is similar to the construction of large-format silicate bricks. But this is a dry assembly method based on a simple modular construction of industrially produced modules. A base sheet is formed from a hollow module with a length of 600 and a height of $300 \mathrm{~mm}$. The various shapes fit together by tongue and groove or pins. The wall stiffens upon the amount of embedded prisms or externally charged batten. The actual hardware is manufactured from dry timber or large format materials, usually OSB. The cavity is filled in thermal insulation mineral wool, recycled paper, cork and the like. Installation does not require complex mechanical properties and means of transport are efficient and fast. The required insulation thickness is achieved by thick insulating fillers but also by reversible lining. (see Figs. 4 - 5).

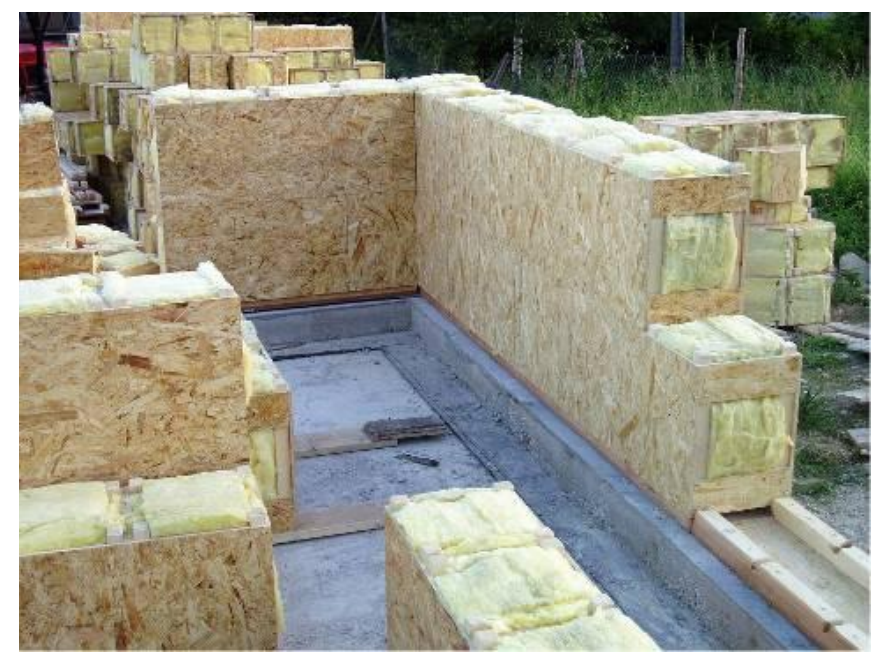

Fig. 4: Construction system of modules based on OSB -boards filled with mineral wool [5]. 


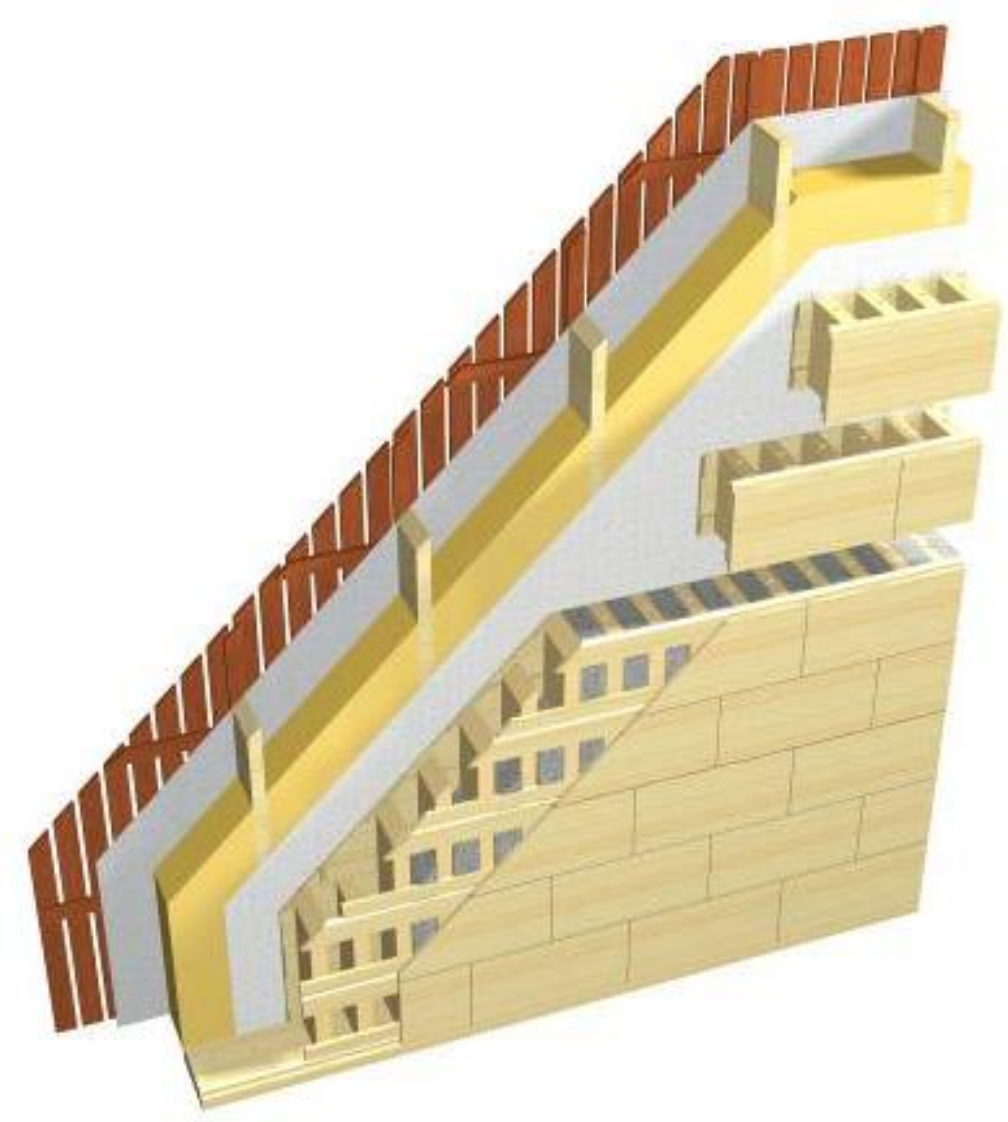

Fig. 5: Types of composite wall fittings with additional external thermal insulation in slats [5].

Fire resistance in this case indicates the composition of the shell and its integrity. When stopping shell and penetration of fire into the fittings there is a problem with extinguishment. It should be appreciated that the actual firefighting work may infringe the fittings unaffected by fire. It is necessary to consider the construction of a good jacket and fire protection systems that are able to eliminate fire in its bud and ensure that we do not have to perform extinguishing its higher volume.

\subsection{Cladding with a carrier layer of glued wood}

Perspective and trendy solution envelope for NED and for passive buildings are massive elements of glued laminated timber or cross laminated timber. A layer of wood glued to the interior side performs mainly a support function. A layer of insulation is added towards the exterior along with the other layers of the structure. Such an arrangement of layers can eliminate thermal bridges occurring at the connection of the peripheral wall to the ceiling and roof decks. Layer of glued wood has better storage properties which favorably affect the indoor climate fluctuations. Finally, we cannot forget the aesthetic value of glued wood which is important to eliminate its obvious defects, such as knots, cracks and the like. (see Fig.6).

Laminated timber from fire light appears to be better from the material point of view. In the case of a fire of laminated timber and when the fire extinction doesn't damage it, the claims can be smaller and reconstruction is less expensive. The fire test shows that the best type of a laminated timber is five-layered timber, because triple layers cannot verify the fire resistance test - integrity. 


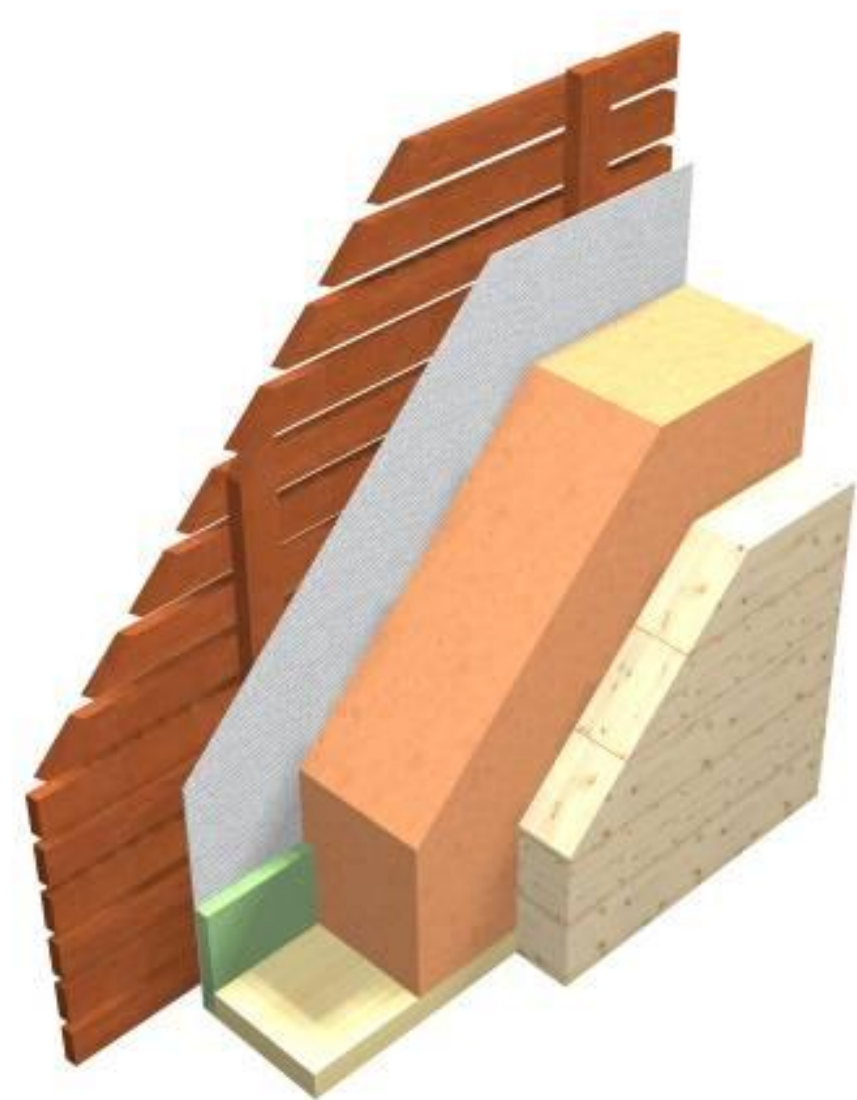

Fig. 6: Types of wall construction made of solid wood and laminated wood [5].

\section{Conclusions}

Each material has its positives and negatives. The main negative wood properties are low biological resistance and the ability of wood to ignite and burn. These negative characteristics, however, are also not the timber, but it is always referenced to timber and human. So it is with a reaction to fire, with an ability to ignite and burn. As in the case of biotic degradation, the same fact comes with the burning of wood - if a person is aware of this characteristic of wood, he is able to eliminate the risk of fire and wood can so serve and fulfill the functions expected by his user. Elimination of the negative qualities of wood can be done by several ways. We can find these methods and based on legal regulations and technical solutions can eliminate mentioned negative qualities as much as possible [8].

\section{References}

[1] Council Directive 89/106/EEC of 21 December 1988 on the approximation of laws, regulations and administrative provisions of the Member States relating to construction products.

[2] ORAVEC, M.: Risk assessment in road tunnels. Košice : EQUILIBRIA 2008, ISBN 978-80-8928419-1.

[3] http://www.steelconstruction.info/Fire_testing (4.2.2015).

[4] BUCHANAN, A.: Structural design for fire safety, West Sussex: John Wiley \& Sons, Ltd.2001, ISBN 0471-89060-X.

[5] OSVALD, A. - ŠTEFKO, J.: Wooden currently low energy construction in terms of fire safety. Building materials 4-5/2012, ročník 8, Košice : V.O.Č Slovakia s.r.o. Publishing journals, s. 48 51. ISSN 1336-6041.

[6] ČESELSKÁ, T. - NETOPILOVÁ, M.: Proposal wooden structures exposed to fire. In: Security of buildings 2007. Ostrava: VŠB - TUO, FBI, 2007, s. 44 - 54. ISBN 978-80-7385-001-2. 
[7] NETOPILOVÁ, M.: Materials - Building materials. VŠB-TUO, FBI, Ostrava, 2004, ISBN 80-8663427-2.

[8] OSVALD, A.: Wooden building $\neq$ fire. Zvolen: Technical University in Zvolen, 2011, 336 s. ISBN 978-80-228-2220-6. 